\title{
Hypoxia reduces cell attachment of SARS-CoV-2 spike protein by modulating the expression of ACE2, neuropilin-1, syndecan-1 and cellular heparan sulfate
}

Endika Prieto-Fernández, Leire Egia-Mendikute, Laura Vila-Vecilla, Alexandre Bosch, Adrián Barreira-Manrique, So Young Lee, Ana García-del Río, Asier Antoñana-Vildosola, Borja Jiménez-Lasheras, Leire Moreno-Cugnon, Jesús Jiménez-Barbero, Edurne Berra, June Ereño-Orbea \& Asis Palazon

To cite this article: Endika Prieto-Fernández, Leire Egia-Mendikute, Laura Vila-Vecilla, Alexandre Bosch, Adrián Barreira-Manrique, So Young Lee, Ana García-del Río, Asier Antoñana-Vildosola, Borja Jiménez-Lasheras, Leire Moreno-Cugnon, Jesús Jiménez-Barbero, Edurne Berra, June Ereño-Orbea \& Asis Palazon (2021) Hypoxia reduces cell attachment of SARS-CoV-2 spike protein by modulating the expression of ACE2, neuropilin-1, syndecan-1 and cellular heparan sulfate, Emerging Microbes \& Infections, 10:1, 1065-1076, DOI: $10.1080 / 22221751.2021 .1932607$

To link to this article: https://doi.org/10.1080/22221751.2021.1932607

a (C) 2021 The Author(s). Published by Informa UK Limited, trading as Taylor \& Francis Group.

Submit your article to this journal ¿
2021.

III Article views: 497 


\title{
Hypoxia reduces cell attachment of SARS-CoV-2 spike protein by modulating the expression of ACE2, neuropilin-1, syndecan-1 and cellular heparan sulfate
}

\author{
Endika Prieto-Fernández (10), Leire Egia-Mendikute (10), Laura Vila-Vecilla (10), Alexandre Bosch (10), \\ Adrián Barreira-Manrique (10 ${ }^{a}$, So Young Lee ${ }^{a}{ }^{a}$, Ana García-del Río (1) ${ }^{a}$, Asier Antoñana-Vildosola (10)

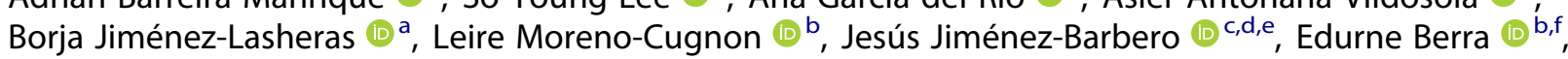 \\ June Ereño-Orbea (10,e and Asis Palazon (1) ${ }^{\mathrm{a}, \mathrm{e}}$
}

\begin{abstract}
${ }^{a}$ Cancer Immunology and Immunotherapy Lab, Centre for Cooperative Research in Biosciences (CIC bioGUNE), Basque Research and Technology Alliance (BRTA), Bizkaia Technology Park, Building 801A, Derio, Spain; ${ }^{\mathrm{b}}$ Cancer Cell Signaling and Metabolism Lab, Centre for Cooperative Research in Biosciences (CIC bioGUNE), Basque Research and Technology Alliance (BRTA), Bizkaia Technology Park, Building 801A, Derio, Spain; 'Chemical Glycobiology Lab, Centre for Cooperative Research in Biosciences (CIC bioGUNE), Basque Research and Technology Alliance (BRTA), Bizkaia Technology Park, Building 800, Derio, Spain; ${ }^{d}$ Department of Organic Chemistry II, Faculty of Science and Technology, University of the Basque Country (UPV/EHU), Leioa, Spain; ${ }^{\mathrm{e}}$ kerbasque, Basque Foundation for Science, Bilbao, Spain; ${ }^{f}$ CIBERONC (Centro de Investigación Biomédica en Red de Cáncer), Madrid, Spain
\end{abstract}

\begin{abstract}
A main clinical parameter of COVID-19 pathophysiology is hypoxia. Here we show that hypoxia decreases the attachment of the receptor-binding domain (RBD) and the S1 subunit (S1) of the spike protein of SARS-CoV-2 to epithelial cells. In Vero E6 cells, hypoxia reduces the protein levels of ACE2 and neuropilin-1 (NRP1), which might in part explain the observed reduction of the infection rate. In addition, hypoxia inhibits the binding of the spike to $\mathrm{NCl}-\mathrm{H} 460$ human lung epithelial cells by decreasing the cell surface levels of heparan sulfate (HS), a known attachment receptor of SARS-CoV-2. This interaction is also reduced by lactoferrin, a glycoprotein that blocks HS moieties on the cell surface. The expression of syndecan-1, an HS-containing proteoglycan expressed in lung, is inhibited by hypoxia on a HIF-1adependent manner. Hypoxia or deletion of syndecan-1 results in reduced binding of the RBD to host cells. Our study indicates that hypoxia acts to prevent SARS-CoV-2 infection, suggesting that the hypoxia signalling pathway might offer therapeutic opportunities for the treatment of COVID-19.
\end{abstract}

ARTICLE HISTORY Received 3 February 2021; Revised 15 May 2021; Accepted 18 May 2021

KEYWORDS SARS-CoV-2; hypoxia; ACE2; heparan sulfate; syndecan-1

\section{Introduction}

By mid-May of 2021, SARS-CoV-2 has infected over 160 million people and caused $>3.3$ million deaths. Until now, more than 1200 million vaccines have been administered. However, the efficacy of available vaccines against emerging variants remains unclear $[1,2]$. Therefore, the need of effective treatments to prevent the infection or to manage the disease in severe cases of COVID-19 remains an urgent medical need.

The spike protein of SARS-CoV-2 interacts with the angiotensin-converting enzyme 2 (ACE2), a keyreceptor widely expressed on the respiratory tract, through the receptor-binding domain (RBD) [3-5]. Other factors such as neuropilin-1 (NRP1) [6,7] and the transmembrane protease serine 2 (TMPRSS2) [8] contribute to the entry of SARS-CoV-2 into host cells. Another layer of interaction between the virus and the host that facilitates viral entry is the attachment of the spike protein to cellular heparan sulfate (HS) [5]. HS is part of the cellular glycocalyx and decorates the HS-containing proteoglycans (HSPGs). The family of syndecans are HSPGs expressed on several cell types and organs [9], being syndecan-1 the most relevant in terms of expression in the lung [10]. The interaction between the spike and HS can be efficiently blocked by lactoferrin [11].

A common feature of COVID-19 patients is moderate to severe hypoxia [12-15]. Disease severity correlates with the level of naturally occurring antiSARS-CoV-2 antibodies in serum [16], and patients with severe disease are characterized by low oxygen saturation that often results in the need for oxygen supplementation [17]. Currently, the impact of hypoxia on SARS-CoV-2 infectivity and COVID-19 pathogenesis is unclear, but there are emerging indications that low oxygen concentrations might prevent infection or disease severity $[18,19]$. This notion is

CONTACT Asis Palazon apalazon@cicbiogune.es $\Theta$ Cancer Immunology and Immunotherapy Lab, Centre for Cooperative Research in Biosciences (CIC bioGUNE), Basque Research and Technology Alliance (BRTA), Bizkaia Technology Park, Building 801A, Derio, Spain

(c) 2021 The Author(s). Published by Informa UK Limited, trading as Taylor \& Francis Group.

This is an Open Access article distributed under the terms of the Creative Commons Attribution License (http://creativecommons.org/licenses/by/4.0/), which permits unrest ricted use, distribution, and reproduction in any medium, provided the original work is properly cited. 
supported, in part, by the fact that epidemiological data indicate that COVID-19 severity decreases in high altitude areas [20].

There is evidence that hypoxia regulates the expression of ACE2, but the underlying mechanisms and impact on physiology and disease remain controversial. Previous studies have demonstrated that regulation of ACE2 expression by hypoxia is contextspecific and cell type- and time-dependent [21-25]. Elucidating these mechanisms in lung epithelial cells would help to understand the cellular susceptibility to infection by SARS-CoV-2 under limited oxygen availability. Additionally, the members of the syndecan family, the main cellular HSPGs, are also differentially regulated by hypoxia. For example, the expression of syndecan-1 in the lungs is reduced under hypoxia [26,27].

Cell responses to hypoxia are mediated by the family of hypoxia inducible factors (HIF). COVID19 disease leads to the accumulation of HIF in the lung, providing a molecular link between SARSCoV-2 infection and hypoxia in patients with severe disease [28]. Our hypothesis is that hypoxia modulates the expression of entry receptors and attachment factors on host cells. In this context, elucidating the underlying mechanisms of this regulation could lead to the development of novel therapeutic strategies for the management of COVID-19, including those targeting the hypoxia response pathway.

\section{Materials and methods}

\section{Cell culture}

The NCI-H460 human lung epithelial cell line was obtained from DSMZ (German Collection of Microorganisms and Cell Lines Cat\#: ACC737) and cultured in RPMI medium 1640 GlutaMAX (Gibco Cat\#: 61870044) according to standard culture protocols. Vero E6 monkey kidney cells (ATCC Cat\#: CRL1586) were kindly provided by Nicola G.A. Abrescia (CIC bioGUNE) and cultured in MEM (Gibco Cat\#: 31095-029). HEK 293T cells (Takara Bio Inc. Cat\#: 632180) were cultured in DMEM (Gibco Cat\#: 41966029). Media were supplemented with $10 \%$ FBS (Thermo Fisher Cat\#: 10270106) and 1\% Penicillin-Streptomycin (Thermo Fisher Cat\#: 15140122). Hypoxia cultures were performed at $1 \% \mathrm{O}_{2}$ and $5 \% \mathrm{CO}_{2}$ in an In Vivo2 400 hypoxia station (Ruskinn Technologies).

\section{Lactoferrin assay}

Binding of RBD to the surface of cells was measured by flow cytometry after incubation with increasing doses of human lactoferrin $(0,1,5$ and $10 \mathrm{mM})$ (Sigma Aldrich Cat\#: L1294) in a final volume of $100 \mu \mathrm{L}$ of culture medium. The incubation was done for $45 \mathrm{~min}$ in a cell incubator with standard conditions $\left(37^{\circ} \mathrm{C}, 21 \% \mathrm{O}_{2}\right.$ and $\left.5 \% \mathrm{CO}_{2}\right)$.

\section{Assessment of binding of RBD and S1 to the cell surface}

After culture, cells were collected with cell dissociation buffer (Thermo Fisher Cat\#: 13151-014), distributed in 96-well polystyrene conical bottom plates (Thermo Fisher Cat\#: 249570) and washed with PBS (Fisher BioReagents Cat\#: BP3994) containing 0.5\% BSA (Sigma Aldrich Cat\#: A9647) (blocking buffer) followed by centrifugation and the supernatant was discarded. Cells were incubated with biotinylated S1 (Acrobiosystems Cat\#: S1N-C82E8) or RBD (Acrobiosystems Cat\#: SPD-C82E9) proteins $(20 \mu \mathrm{g} / \mathrm{mL})$ in $50 \mu \mathrm{L}$ of blocking buffer for $30 \mathrm{~min}$ at $4^{\circ} \mathrm{C}$. After incubation, cells were centrifuged, washed with $200 \mu \mathrm{L}$ of blocking buffer, centrifuged again and incubated with streptavidin-PE (Thermo Fisher Cat\#: 12-431787) diluted in $100 \mu \mathrm{L}$ of blocking buffer (1:200 dilution). Finally, cells were centrifuged and washed twice and resuspended in blocking buffer with DAPI (Invitrogen Cat\#: D1306) for acquisition in the flow cytometer. All centrifugation steps were performed at $300 \mathrm{~g}$ for $5 \mathrm{~min}\left(4^{\circ} \mathrm{C}\right)$.

\section{Generation of pseudotyped lentiviral particles}

Pseudotyped lentiviral particles were generated by transfecting HEK 293T cells as described in Crawford et al. [29], using a five-plasmid third-generation system kindly provided by Dr Jesse D. Bloom (Fred Hutchinson Cancer Research Center) and Dr JeanPhilippe Julien (University of Toronto). Confluent HEK 293T cells (50-70\%) were transfected with plasmids encoding for the lentiviral backbone (containing a CMV promoter to express ZsGreen) (NR-52520, $5.79 \mu \mathrm{g}$ ), the SARS-CoV-2 spike protein (NR-52514, $1.97 \mu \mathrm{g}$ ), HDM-Hgpm2 (NR-52517, $1.27 \mu \mathrm{g}$ ), pRCCMV-Rev1b (NR-52519, $1.27 \mu \mathrm{g}$ ) and HDM-tat1b (NR-52518, $1.27 \mu \mathrm{g}$ ) using the jetPEI kit (Polyplustransfection Cat\#: 101-10N). $48 \mathrm{~h}$ after transfection, viruses were harvested from the supernatant, filtered through a $0.45 \mu \mathrm{m}$ filter (VWR Cat\#: 514-0063), concentrated using Lenti-X Concentrator (Takara Bio Inc. Cat\#: 631231) and stored in PBS at $-80^{\circ} \mathrm{C}$ until use.

\section{Titration of the pseudotyped lentiviral particles and infection of Vero E6 cells}

Viral titration was performed in Vero E6 cells as described in Crawford et al. [29]. For single-infection experiments, 150,000 cells were seeded in 6-well plates and cultured overnight in normoxia $\left(21 \% \mathrm{O}_{2}\right)$ and incubated for additional $24 \mathrm{~h}$ under normoxia or hypoxia $\left(1 \% \mathrm{O}_{2}\right)$. After that, cells were incubated with the 
pseudotyped lentiviral particles (MOI: 0.1 ) for $48 \mathrm{~h}$ under normoxic conditions. The infected cells expressed ZsGreen, allowing their detection by flow cytometry.

\section{Deletion of HIF-1a and syndecan-1 in NCI-H46O cells via CRISPR/Cas9}

Deletion of HIF-1a in NCI-H460 cells was performed using a pool of two sgRNAs from Synthego (sgRNA sequences: gaugguaagccucaucacag and guuuuccaaacuccgacauu) and the TrueCut Cas9 protein v2 (Invitrogen Cat\#: A36497). Deletion of syndecan-1 was performed using the following TrueGuide Synthetic sgRNAs from Invitrogen: CRISPR913712_SGM and CRISPR913714_SGM. RNP-complexes were generated with 7.5 pmol of Cas9, 7.5 pmol of the sgRNA-1 and 7.5 pmol of the sgRNA-2. RNP-complexes were introduced into cells using the Lipofectamine CRISPRMAX Cas9 Transfection reagent (Invitrogen Cat\#: CMAX00001) and Opti-MEM reduced serum medium (Gibco Cat\#: 31985062) following the Pub. No. MAN0017058 by Invitrogen (pages 5 and 6). A nontargeting sgRNA that does not recognize any sequence in the human genome was used as a negative control (Invitrogen Cat\#: A35526). The deletion efficiency of HIF- $1 \alpha$ and syndecan- 1 proteins was measured by western blot and flow cytometry, respectively, and the pool of edited cells was used for downstream experiments.

\section{Flow cytometry}

Cells were collected, washed with blocking buffer and incubated with fluorochrome-conjugated antibodies (1:100 dilution in blocking buffer) against syndecan1 (BD Biosciences Cat\#: 565943), syndecan-2 (R\&D Systems Cat\#: FAB2965P), syndecan-3 (R\&D Systems Cat\#: FAB3539A) and syndecan-4 (R\&D Systems Cat\#: FAB291819) for $15 \mathrm{~min}$ at $4^{\circ} \mathrm{C}$. Total cellular HS was measured by flow cytometry after incubation for $30 \mathrm{~min}$ at $4^{\circ} \mathrm{C}$ with an anti-HS primary antibody (Amsbio Cat\#: 370255-S; clone F58-10E4) (1:200 dilution in blocking buffer). After that, cells were centrifuged, washed and incubated with an anti-IgM FITC-conjugated secondary antibody (Miltenyi Biotec Cat\#: 130-095-906) (1:500 dilution in blocking buffer). Finally, cells were centrifuged, washed twice and resuspended in $200 \mu \mathrm{L}$ of blocking buffer in the presence of 7-AAD (BD Biosciences Cat\#: 51-68981E) or DAPI (Invitrogen Cat\#: D1306) to discriminate alive cells. Cells were acquired on a FACSymphony cytometer (BD Biosciences). The results were analysed using FlowJo version 10 (BD Biosciences).

\section{Quantitative PCR}

Total RNA was isolated using the NucleoSpin RNA kit (Macherey-Nagel Cat\#: 740955.250). The cDNA was synthesized by RT-PCR from $1 \mu \mathrm{g}$ of purified RNA with the M-MLV reverse transcriptase (Thermo Fisher Cat\#: 28025-013) and random primers (Thermo Fisher Cat\#: 58875). Quantitative PCR (Q-PCR) reactions were conducted in triplicate on a ViiA 7 RealTime PCR system (Thermo Fisher) from $1 \mu \mathrm{L}$ of cDNA using the PerfeCTa SYBR Green SuperMix reagent (Quantabio Cat\#: 95056-500) and genespecific primers. The amplification programme consisted of initial denaturation at $95^{\circ} \mathrm{C}$ for 3 min followed by 40 cycles of denaturation at $95^{\circ} \mathrm{C}$ for $15 \mathrm{~s}$, annealing at $60^{\circ} \mathrm{C}$ for $60 \mathrm{~s}$ and extension at $72^{\circ} \mathrm{C}$ for 60 s. Data were analysed using the QuantStudio software version 1.3 (Thermo Fisher). The relative quantification in gene expression was determined using the $2^{-\triangle \Delta \mathrm{Ct}}$ method by using the RPLPO gene as a housekeeping gene (forward: 5'-CGACCTGGAAGTCCAACTAC-3' and reverse: $5^{\prime}$-ATCTGCTGCATCTGCTTG-3'). PGK1, a HIF-1 1 target gene, was used as a control for hypoxia (forward: $5^{\prime}$ CCGCTTTCATGTGGAGGAAGAAG- $3^{\prime}$ and reverse: 5'-CTCTGTGAGCAGTGCCAAAAGC-3'). Primer sequences for measuring $A C E 2$ and $S D C 1$ expression on human NCI-H460 cells were previously described by $\mathrm{Ma}$ et al. [30] and Reynolds et al. [31], respectively. As these oligos presented several mismatches with the corresponding genes on the reference genome of the African green monkey, we designed the following primers to amplify ACE2 from Vero E6 cells (forward: $5^{\prime}$ AGCACTCACGATTGTTGGGA-3' and reverse: $5^{\prime}$ CCACCCCAACTATCTCTCGC-3').

\section{Western blot}

Total cell lysates were collected using RIPA buffer and quantified with the BCA Protein Assay kit (Thermo Fisher Cat\#: 23227). Samples were mixed with LDS sample buffer (Invitrogen Cat\#: NP0007) containing DTT, boiled for $15 \mathrm{~min}$, separated in a $4-15 \%$ MiniPROTEAN TGX precast protein gels (BioRad Cat\#: 4561083) and transferred to a $0.2 \mu \mathrm{m}$ PVDF membranes (BioRad Cat\#: 1704156) using a Trans-Blot Turbo transfer system (BioRad). PageRuler protein ladder (Thermo Fisher Cat\#: 26619) was used to estimate the molecular weight of the proteins. The membranes were blocked for $1 \mathrm{~h}$ in $5 \%$ skim milk (Millipore Cat\#: 70166) and 0.5\% Tween-20 (Sigma Aldrich Cat\#: 9005-64-5) diluted in PBS. The membranes were probed overnight at $4^{\circ} \mathrm{C}$ with primary antibodies diluted in PBS containing 5\% BSA and $0.5 \%$ Tween-20, washed five times with PBS (containing $0.5 \%$ Tween-20), incubated for $1 \mathrm{~h}$ at RT with the corresponding secondary HRP-conjugated antibodies (1:5000 diluted in 5\% skim milk and 0.5\% Tween-20 diluted in PBS) and washed for five additional times. The membranes were probed with antibodies against HIF-1a (Novus Biologicals Cat\#: NB100-449), ACE2 
(Bioss antibodies Cat\#: bsm-52614R), NRP1 (Novus Biologicals Cat\#: NBP2-67539), TMPRSS2 (Novus Biologicals Cat\#: NBP3-00492), $\beta$-actin (Cell Signalling Cat\#: D6A8) and $\beta$-tubulin (Thermo Fisher Cat\#: MA5-16308). HRP-conjugated secondary antibodies against mouse (Cat\#: S301677076S) and rabbit (Cat\#: S301677074S) were obtained from Cell Signalling. Chemiluminescence detection was performed using Clarity Max Western ECL Substrate (BioRad Cat\#: 170506) on an iBright system (Invitrogen). Band densitometry was performed using ImageJ (https://imagej.nih.gov/ij/).

\section{Statistics}

Statistical analyses were performed using GraphPad Prism version 8.0. The test applied in each panel is specified on the figure legends.

\section{Results}

\section{Hypoxia reduces the binding of the SARS-CoV-2 spike to epithelial cells}

In order to understand if hypoxia could affect the cellular binding capacity of the SARS-CoV-2 spike protein, we subjected Vero E6 cells or human lung epithelial cells (NCI-H460) to different oxygen concentrations $\left(21 \% \mathrm{O}_{2}\right.$ or $\left.1 \% \mathrm{O}_{2}\right)$ and measured the binding ability of the receptor-binding domain (RBD) and the S1 subunit (S1) of the spike protein to the surface of these cells in vitro. Figure 1 shows a significant decrease in the binding of RBD and S1 after culturing Vero E6 (Figure 1(a)) or NCI-H460 (Figure $1(\mathrm{~b})$ ) cells under hypoxia $\left(1 \% \mathrm{O}_{2}\right)$ compared to normoxia $\left(21 \% \mathrm{O}_{2}\right)$.

\section{Hypoxia decreases ACE2 and NRP1 protein levels on Vero E6 cells}

To further explore the mechanism underlying the observed reduced binding of the spike under hypoxia, we assessed ACE2 gene and protein expression on Vero E6 and NCI-H460 cells by Q-PCR and western blot, respectively. Vero E6 cells, but not NCI-H460 cells, present detectable levels of ACE2 transcripts (Figure 2(a)). Accordingly, ACE2 protein is only detectable on Vero E6 cells (Figure 2(b)), suggesting that the observed binding of the spike to the surface of NCI-H460 cells is ACE2-independent. We then explored if hypoxia modulates ACE2 expression on Vero E6 cells. Hypoxia culture results in a transient accumulation of HIF- $1 \alpha$ and upregulation of the expression of ACE2 (Figure 2(b,c)). After $48 \mathrm{~h}$ of exposure to a limited oxygen supply, the level of ACE2 protein on Vero E6 cells is significantly reduced (Figure 2(b)). On a similar manner, we measured the expression of other important factors that mediate the initial steps of SARS-CoV-2 infection: NRP1 and TMPRSS2. NRP1 (but not TMPRSS2) is significantly reduced on Vero E6 cells after culture for $48 \mathrm{~h}$ under hypoxia (Figure 2(d)), as previously described by Casazza et al. [32] on the hypoxic tumour microenvironment. NCI-H460 cells do not express detectable levels of NRP1.

\section{Hypoxia prevents the infection of Vero E6 cells with pseudotyped viral particles expressing the spike protein of SARS-CoV-2}

We then assessed the influence of oxygen availability on the infection capacity of pseudotyped lentiviral particles that express the full-length spike of SARSCoV-2. Vero E6 cells exposed to hypoxia show a significant decrease in the rate of infection (Figure 3 (a)) compared to normoxia. NCI-H460 cells, which lack expression of ACE2 and NRP1 (Figure 2(b,d)), are not amenable to infection (Figure 3(b)).

\section{Lactoferrin blocks the binding of RBD to the surface of epithelial cells}

Recently, it has been demonstrated that the spike of SARS-CoV-2 can bind to HS expressed on the host cell surfaces [5]. We reasoned that this phenomenon might explain the observed binding of RBD to NCIH460 epithelial cells in the absence of ACE2 and NRP1. To confirm this interaction, we blocked cellular HS with human lactoferrin, a natural glycoprotein that binds to HS and presents antiviral activity against coronaviruses $[11,33]$. Figure 4 shows that lactoferrin was able to reduce the attachment of the RBD of SARSCoV-2 to Vero E6 (Figure 4(a)) and NCI-H460 (Figure 4(b)) cells in a dose-dependent manner. Interestingly, the degree of blockade by lower doses of lactoferrin was higher on NCI-H460 compared to Vero E6 cells.

\section{Hypoxia decreases the total level of heparan sulfate on the surface of epithelial cells}

Considering that cellular HS mediates the binding of RBD in NCI-H460 cells lacking the expression of ACE2 and NRP1, we explored if this interaction was altered by hypoxia. Hypoxia significantly decreases the total level of cellular HS present on Vero E6 cells (Figure 5(a)) and, to a higher extent, on NCI-H460 cells (Figure 5(b)). The syndecan family is a major contributor to the pool of HS on the surface of cells. In this context, we assessed the expression levels of syndecan- 1 , syndecan-2, syndecan- 3 and syndecan- 4 on NCI-H460 cells. We found that syndecan-1 and syndecan-3 are the main syndecans expressed on 
a

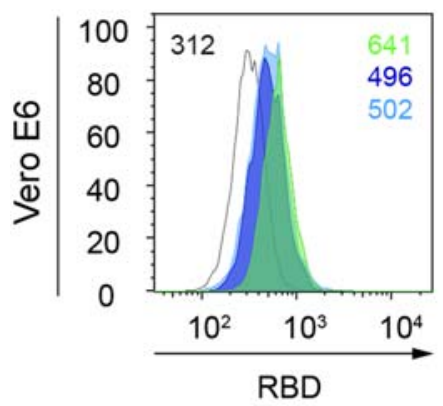

b

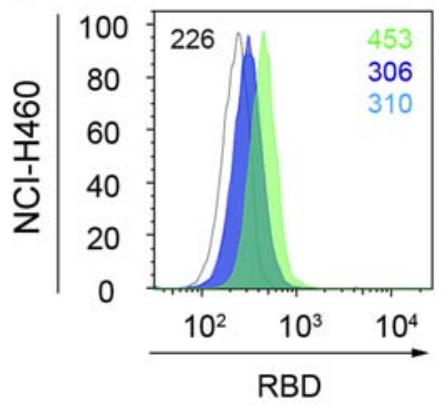

RBD binding
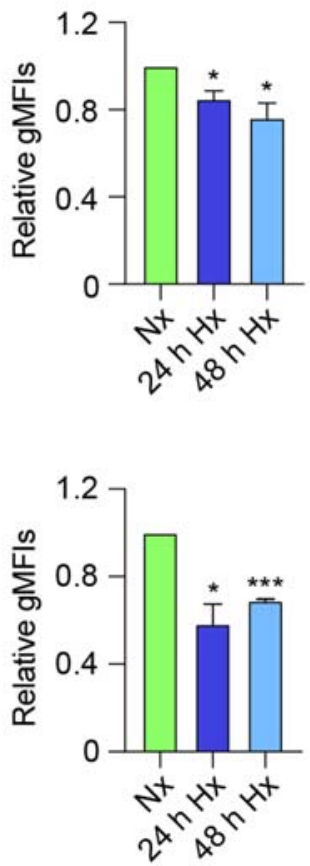

S1 binding
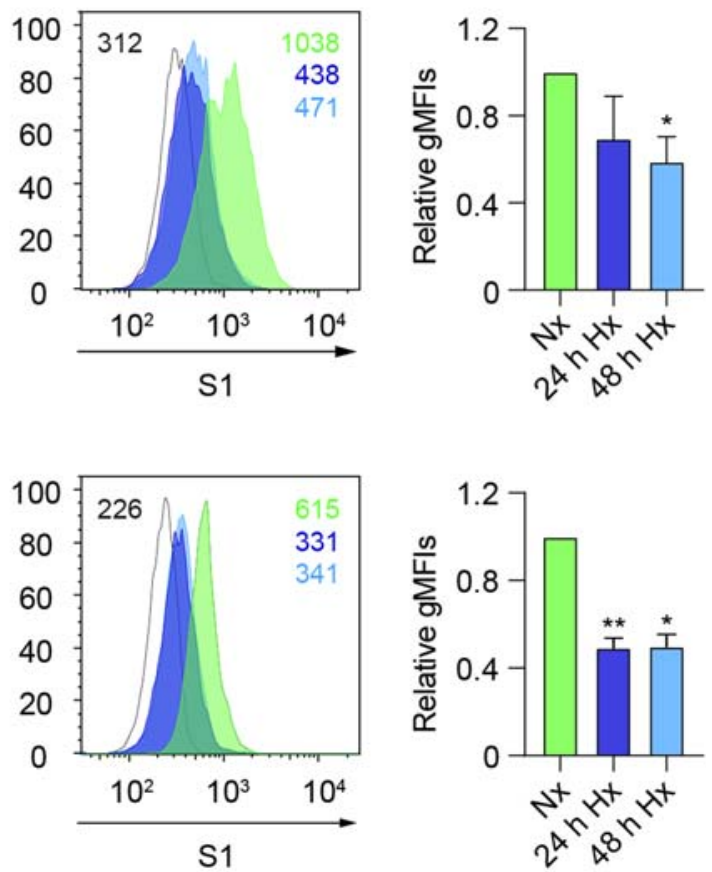

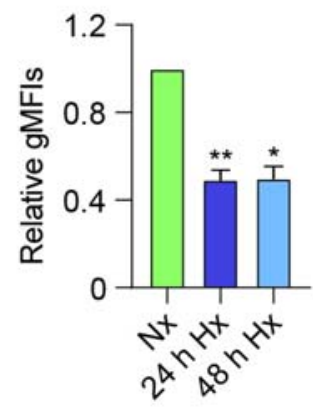

Figure 1. Hypoxia reduces the binding of the SARS-CoV-2 spike to epithelial cells. ( $a$ and $b$ ) Binding of the receptor-binding domain (RBD) (left) or S1 subunit (S1) (right) to Vero E6 (a) ( $n=3$ independent experiments, unpaired $t$ test) or $\mathrm{NCl}-\mathrm{H} 460(b)$ $\left(n=2\right.$ independent experiments, unpaired $t$ test) cells cultured under normoxia $\left(21 \% \mathrm{O}_{2}\right)$ or hypoxia $\left(1 \% \mathrm{O}_{2}\right)$ for 24 and $48 \mathrm{~h}$, measured by flow cytometry. A representative histogram indicating the geometric mean fluorescent intensity (gMFI) value for each condition is shown. Bar graphs represent RBD or S1 binding relative to normoxia. Error bars represent SEM and asterisks represent $p$ values $\left({ }^{*} \leq .05 ;{ }^{* *}<.01 ;{ }^{* * *}<.001\right)$. Abbreviations: SAV-PE: Streptavidin-phycoerythrin; Nx: normoxia $\left(21 \% \mathrm{O}_{2}\right) ; \mathrm{Hx}$ : hypoxia $\left(1 \% \mathrm{O}_{2}\right)$.

this cell model and that hypoxia significantly reduces their expression at protein level (Figure 5(c)).

\section{Hypoxia reduces the binding of RBD to $\mathrm{NCl}$ - H460 epithelial cells by downregulating syndecan-1 expression on a HIF-1a-dependent mechanism}

Based on the finding that syndecan-1 is the most abundantly expressed syndecan on NCI-H460 cells (Figure 5(c)), we sought to ascertain its role in the attachment of the spike protein to host cells. Figure 6(a) shows that NCI-H460 cells expressing high levels of syndecan-1 capture higher amounts of RBD compared to cells expressing low levels of syndecan-1. To further demonstrate the binding of RBD to syndecan-1, we generated a cell line with reduced expression of syndecan-1 via CRISPR/Cas9 (SDC1-KO). A pool of SDC1-edited cells binds less RBD compared to control NCI-H460 cells (Figure 6(b)). Given that HIF-1a is the main transcriptional mediator of the response to hypoxia, we checked if it was responsible for the observed downregulation of syndecan-1 under hypoxia (Figure 5(c) and Figure 6(c)). To this end, we generated HIF-1 $\alpha$ deficient NCI-H460 cells via CRISPR/Cas9 (Figure 6(d)). Deletion of HIF-1a on NCI-H460 cells partially rescued the observed inhibition of syndecan-1 expression under hypoxia (Figure 6(e)), resulting in a marked increase in the total levels of cellular HS (Figure 6(f)). Consequently, the level of RBD binding to HIF1-KO cells under hypoxia was higher than in control HIF-1a competent cells (Figure 6(g)).

\section{Discussion}

COVID-19 disease is associated with hypoxia $[12,28,34]$, which results in decreased oxygen availability for tissues. This phenomenon affects the susceptibility of host cells to viral infections [35] and shapes immune responses [36]. Here, we describe the binding ability of the spike of SARS-CoV-2 to epithelial cells cultured under different oxygen concentrations. We show that hypoxia inhibits the binding of the RBD and the S1 subunit of the spike of SARS-CoV-2 to host cells by modulating the expression of several entry and attachment factors. 


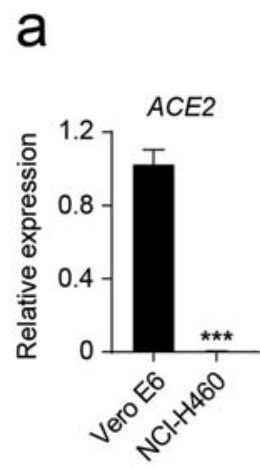

C

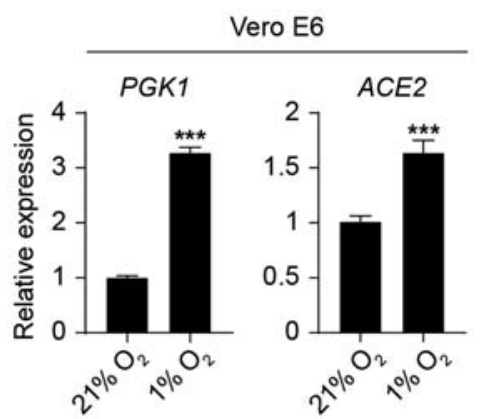

b

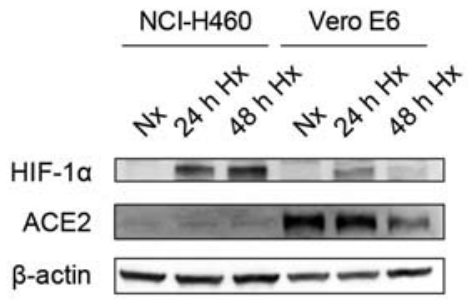

d

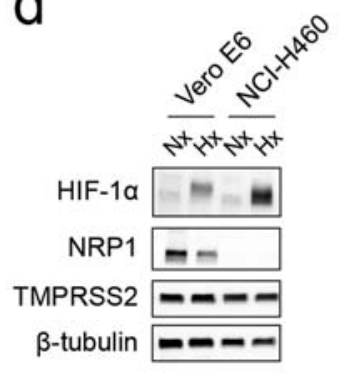

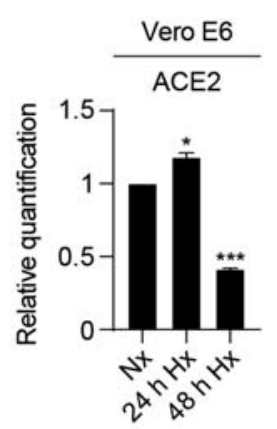

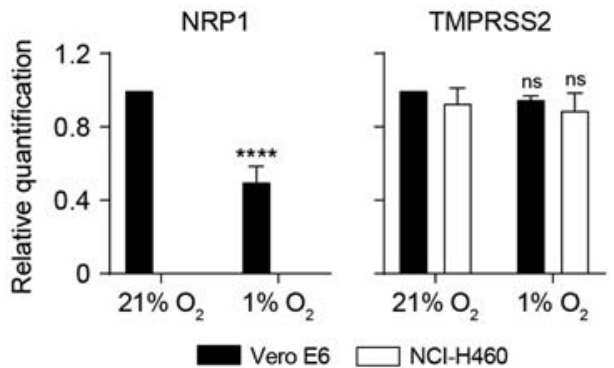

Figure 2. Hypoxia decreases ACE2 and NRP1 protein levels on Vero E6 cells. (a) Relative ACE2 gene expression on Vero E6 and NCIH460 measured by Q-PCR ( $n=3$, unpaired $t$ test). (b) (Left) Western blot of HIF-1a, ACE2 and $\beta$-actin on NCl-H460 and Vero E6 cells cultured under normoxia $\left(21 \% \mathrm{O}_{2}\right)$ or hypoxia $\left(1 \% \mathrm{O}_{2}\right)$ for the indicated time points. (Right) Relative quantification of ACE2 protein expression by densitometry ( $n=2$, one-way ANOVA). (c) Relative gene expression of PGK1 (left) and ACE2 (right) on Vero E6 cells cultured under normoxia or hypoxia for $24 \mathrm{~h}$ ( $n=3$, unpaired $\mathrm{t}$ test). (d) (Left) Western blot of HIF-1a, NRP1, TMPRSS2 and $\beta$-tubulin on Vero E6 and NCl-H460 cells cultured under normoxia or hypoxia for $48 \mathrm{~h}$. (Right) Relative quantification of NRP1 and TMPRSS2 proteins by densitometry $\left(n=3,2\right.$-way ANOVA). Error bars represent SEM and asterisks represent $p$ values $\left({ }^{*} \leq .05\right.$; $\left.{ }^{* * *}<.001 ;{ }^{* * * *}<.0001\right)$.

In this study, we consider two different and complementary cellular models. First, Vero E6 cells, a widely used cell type in SARS-CoV-2 biology research because of its expression of ACE2, NRP1 and TMPRSS2 factors, which are components of the cellular machinery that allow the entry of SARS-CoV-2 into host target cells. Second, NCI-H460 human lung epithelial cells, which lack the expression of ACE2 and NRP1 and as such, do not get infected by pseudotyped viral particles expressing the spike of SARS-CoV-2, but permits the binding of the spike and RBD to cellular HS [11,37]. This dual approach allowed us to investigate the mechanism underlying the observed reduction of RBD binding and infectivity.

Using the Vero E6 model we showed that prolonged hypoxia reduces the expression levels of cell surface ACE2 and NRP1, resulting in a reduced
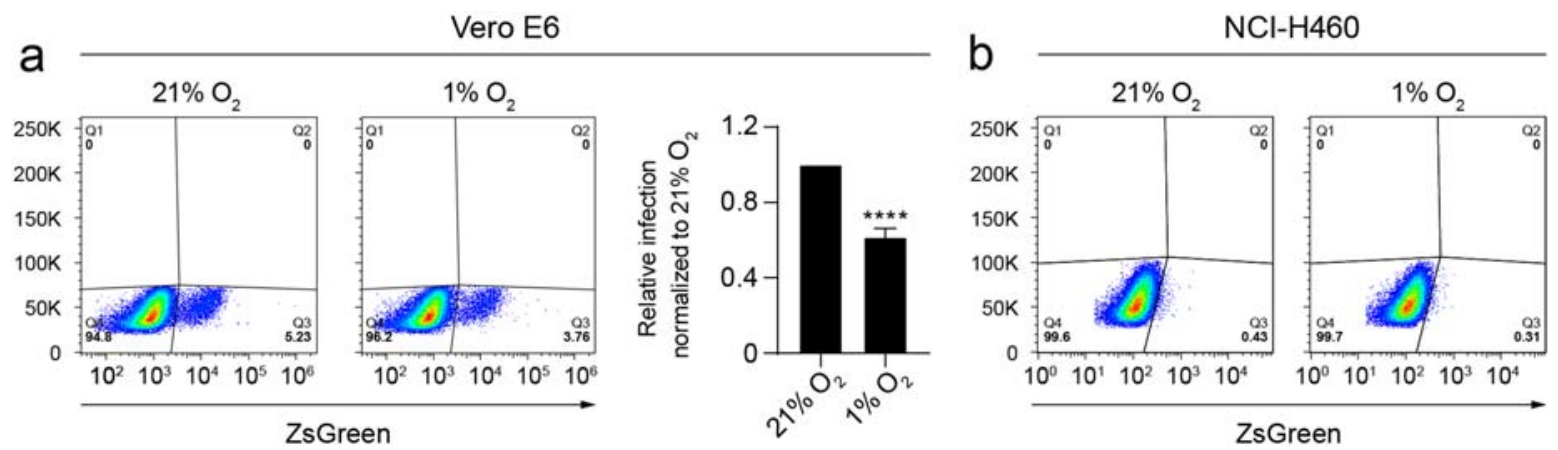

Figure 3. Hypoxia prevents the infection of Vero E6 cells with pseudotyped viral particles expressing the spike protein of SARS-CoV-2. (a) Dot plots representing the infection rate of Vero E6 cells exposed to normoxia $\left(21 \% \mathrm{O}_{2}\right)$ or hypoxia $\left(1 \% \mathrm{O}_{2}\right)$ measured by flow cytometry (ZsGreen expression) $48 \mathrm{~h}$ after addition of the pseudotyped viral particles $(n=6$ independent experiments, unpaired $t$ test). Gating strategy was based on uninfected cells. Bar graphs represent infectivity relative to normoxia. (b) $\mathrm{NCl}-\mathrm{H} 460$ cells are not infected by pseudotyped viral particles. Error bars represent SEM and asterisks represent $p$ values $(* * * * 0001)$. 
SAV-PE control:

\section{RBD binding:}

a

\section{Vero E6}
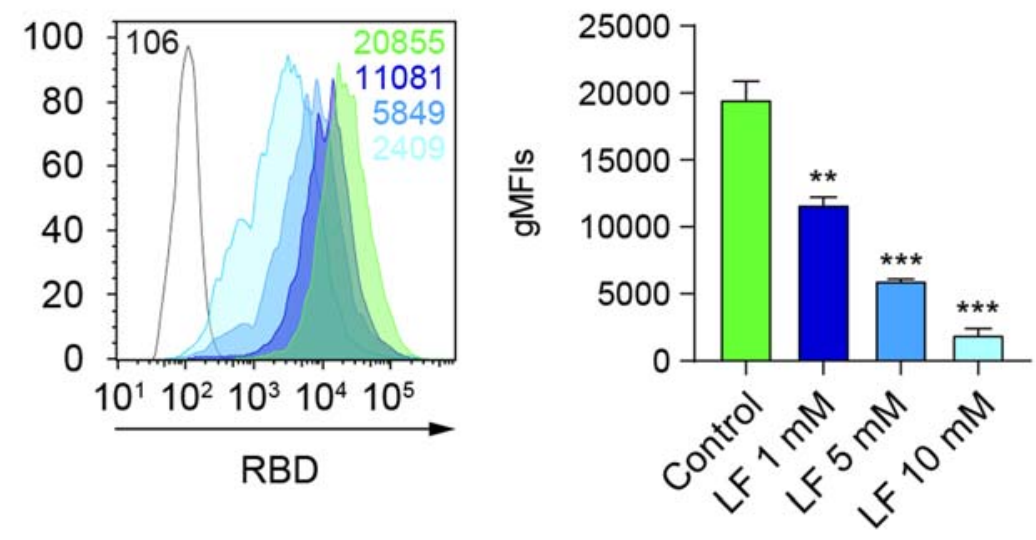

\section{b $\mathrm{NCl}-\mathrm{H} 460$}
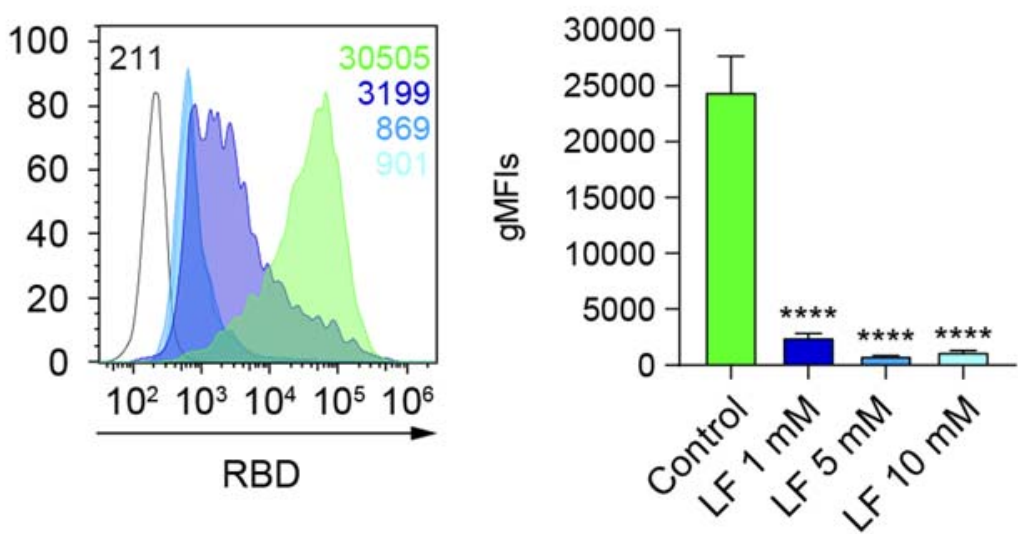

Figure 4. Lactoferrin blocks the binding of RBD to the surface of epithelial cells. (a and b) Binding of RBD to Vero E6 (a) ( $n=2$ independent experiments, one-way ANOVA) or NCl-H460 (b) ( $n=3$ independent experiments, one-way ANOVA) cells cultured under normoxia $\left(21 \% \mathrm{O}_{2}\right)$ for $48 \mathrm{~h}$ measured by flow cytometry after incubation with increasing doses of lactoferrin. A representative flow cytometry histogram indicating the gMFI value for each condition is shown. Error bars represent SEM and asterisks represent $p$ values $\left({ }^{* *}<.01 ;{ }^{* * *}<.001 ;{ }^{* * *}<.0001\right)$.

susceptibility to infection by pseudotyped viral particles expressing the spike of SARS-CoV-2. We have not observed changes in the expression of TMPRSS2 under hypoxia. Previous studies suggest that the expression of ACE2 under hypoxia is context dependent [21-25]. Hypoxia exposure time is one of the variables that influence ACE2 levels. We show that acute hypoxia $(24 \mathrm{~h})$ can induce a transient increase in ACE2 expression, probably mediated by the binding of HIF-1 $\alpha$ to the hypoxia response elements found in the ACE2 promoter $[22,38]$. However, chronic hypoxia ( $48 \mathrm{~h}$ ) leads to a significant reduction of ACE2 and HIF-1a levels on Vero E6 cells. In line with these findings, a recent study shows that hypoxia reduces the protein levels of ACE2 on several cell lines [38].
Cellular HS is known to cooperate with the entry receptor ACE2 as an attachment factor, facilitating the initial capture of viral particles by the cellular glycocalyx [5]. We used NCI-H460 human lung epithelial cells to disentangle the contribution of cellular HS to the observed reduction of infection under hypoxia on an ACE2-independent manner.

First, we confirmed that the RBD binds to HS expressed on target cells by blocking this interaction with lactoferrin. Vero E6 cells are less sensitive than NCI-H460 cells to the blockade exerted by low doses of lactoferrin. This difference could be attributed to the interaction of RBD with other cellular components that are absent in NCI-H460 cells, such as ACE2 and NRP1. These findings prompted us to use NCI-H460 


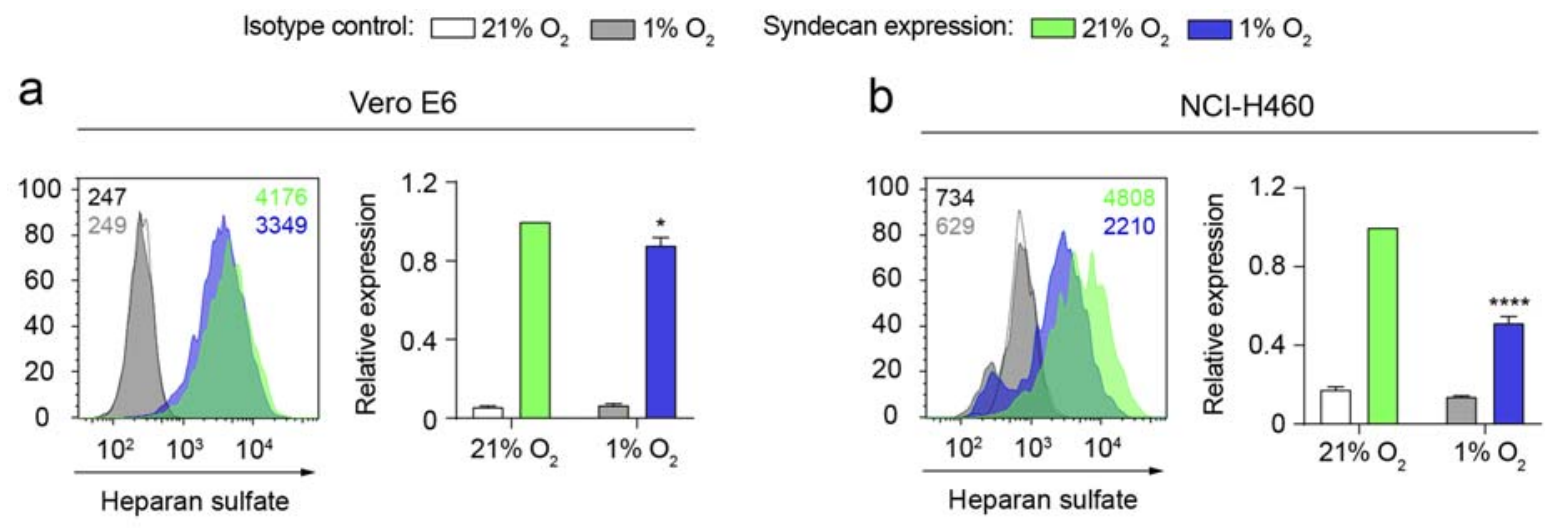

C $\mathrm{NCl}-\mathrm{H} 460$
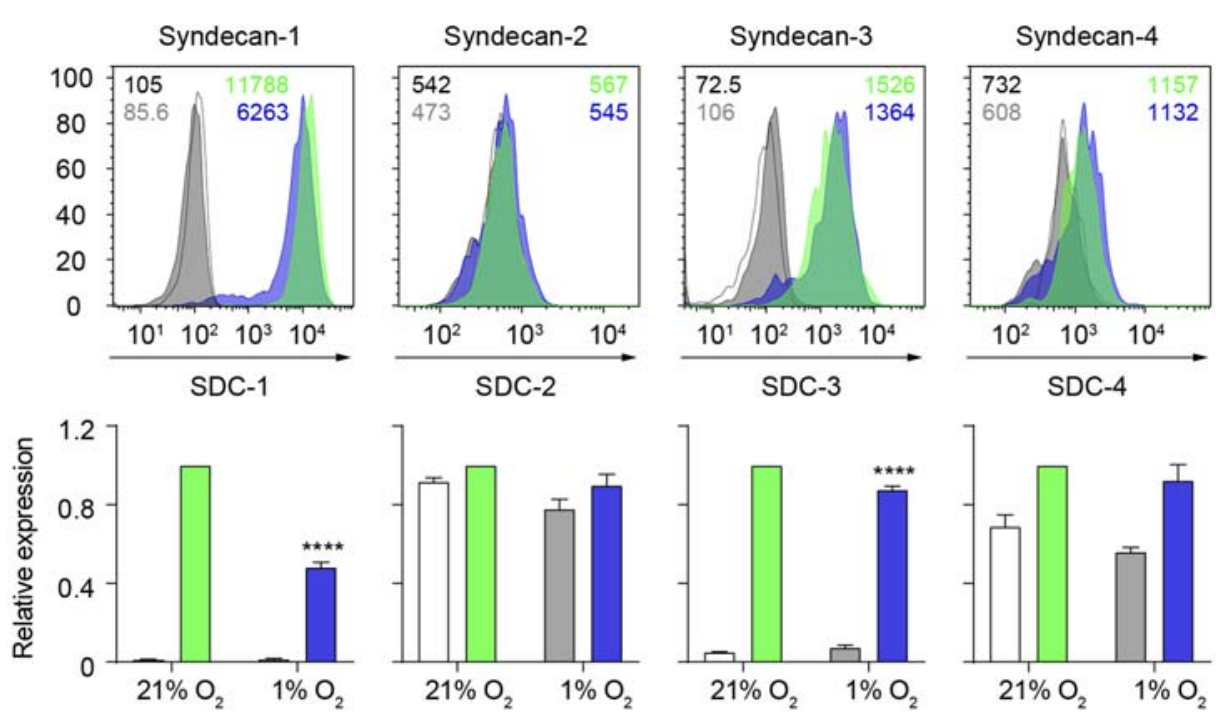

Figure 5. Hypoxia decreases the total level of heparan sulfate on the surface of epithelial cells. (a and b) Total heparan sulfate levels on Vero E6 $(a)$ and $\mathrm{NCl}-\mathrm{H} 460(b)$ cells cultured under normoxia $\left(21 \% \mathrm{O}_{2}\right)$ or hypoxia $\left(1 \% \mathrm{O}_{2}\right)$ for $24 \mathrm{~h}$, measured by flow cytometry. (c) Expression of the syndecan family members on NCl-H460 cells cultured under normoxia or hypoxia for $24 \mathrm{~h}$. Representative flow cytometry histograms including gMFI values are shown. Bar graphs represent syndecan expression levels under hypoxia relative to normoxia ( $n=2$ independent experiments, 2-way ANOVA). Error bars represent SEM and asterisks represent $p$ values $\left({ }^{*} \leq .05 ;{ }^{* * *} \leq .0001\right)$.

cells as a model to assess the effect of hypoxia on the levels of cellular HS and its interaction with the spike of SARS-CoV-2.

We showed that hypoxia leads to a significant reduction of the cellular pool of HS on NCI-H460 cells. Interestingly, syndecan-1, which is expressed in the lung [10], is responsible for this decrease under hypoxia. We confirmed this finding by measuring the binding of RBD to cells expressing different amounts of syndecan-1. We then wanted to ascertain if HIF-1a was responsible for the reduction of the expression of syndecan-1 observed under hypoxia at both transcriptional and protein expression levels. Ablation of HIF-1a in NCI-H460 cells demonstrated that HIF-1 $\alpha$ is necessary for the inhibition of syndecan-1 expression under hypoxia. Moreover, deletion of HIF-1 $\alpha$ results in an increase of cellular HS levels and higher binding capacity of RBD to hypoxic NCI-H460 cells.
Together, these results indicate that the hypoxia response governed by HIF-1 $\alpha$ in the host target cells leads to a protective effect against SARS-CoV-2 infection. In this context, the administration of HIF prolylhydroxylase (PHD) inhibitors that result in the accumulation of HIF-1a may serve as a potential treatment to limit the initial attachment and entry of the virus into host cells $[38,39]$. It should be noted that as the infection progresses into COVID-19 disease, exacerbated inflammatory responses contribute to severity. Inflammation and the response to hypoxia are closely related processes that coexist in certain microenvironments [40,41]. Macrophages are important mediators of lung inflammation during COVID-19 disease [42]. As a result of hypoxia in the lung, elevated HIF- $1 \alpha$ activity on immune innate cells contributes to severity $[43,44]$. In this scenario, promoting systemic HIF-1 $\alpha$ activity through pharmacological intervention in severe COVID-19 patients might be detrimental. 
a

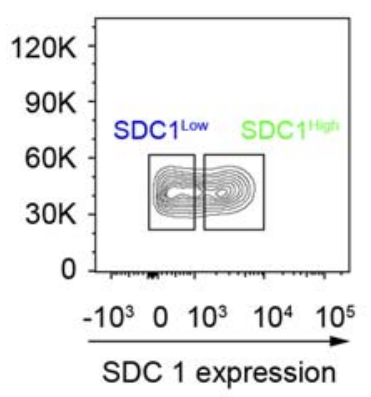

Isotype control

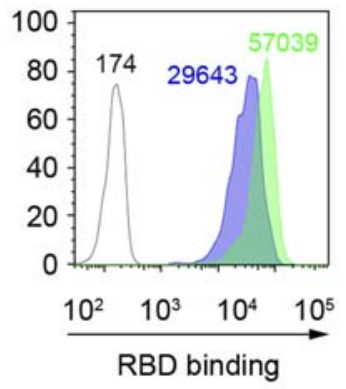

$\mathrm{SDC}^{1 \text { low }} \square \mathrm{SDC}^{\text {Hith }}$ b

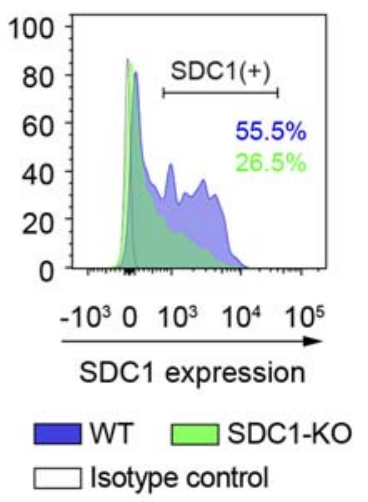

RBD binding

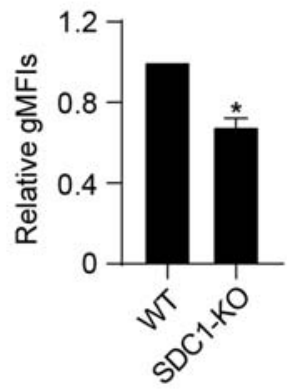

C

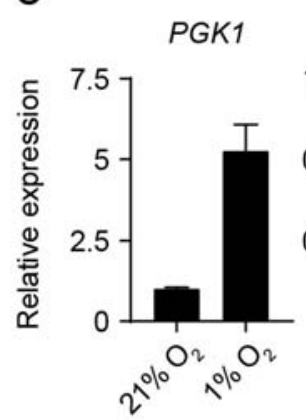

f

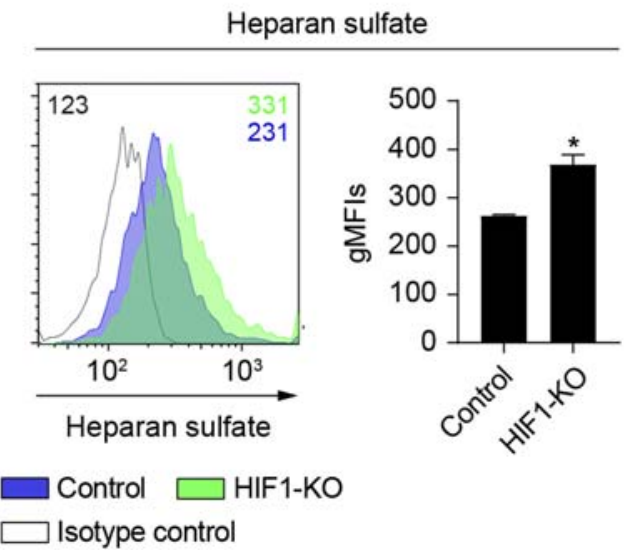

d

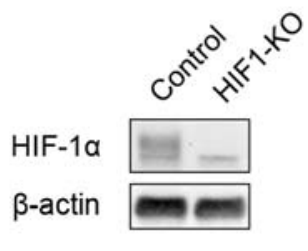

e

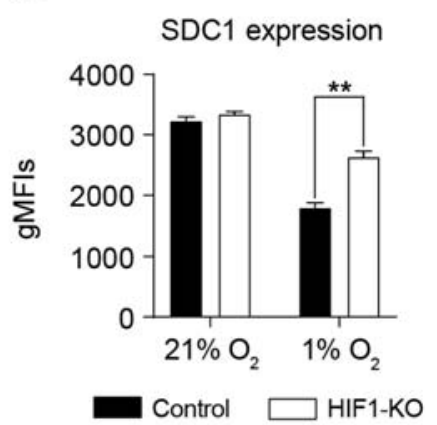

RBD binding

g

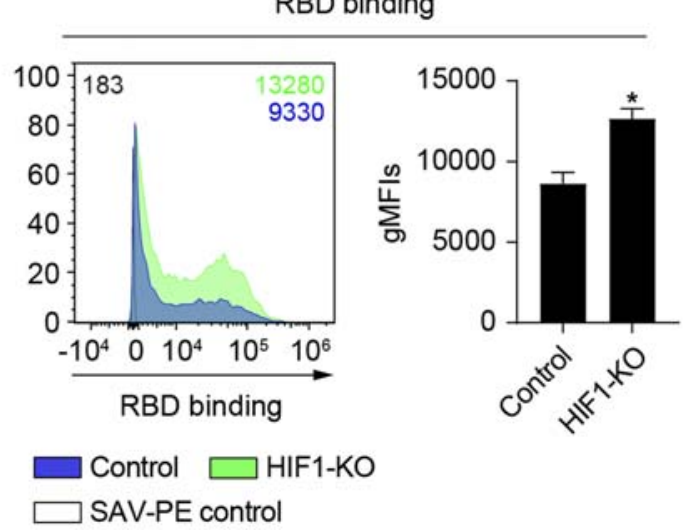

Figure 6. Hypoxia reduces the binding of RBD to $\mathrm{NCl}-\mathrm{H} 460$ epithelial cells by downregulating syndecan-1 expression on a HIF-1adependent mechanism. (a) (Left) Gating strategy followed to select cells expressing high (SDC1 ${ }^{\text {High }}$ ) or low (SDC1 ${ }^{\text {Low }}$ ) levels of syndecan-1 under normoxia. (Right) Representative flow cytometry histogram showing the binding of RBD to SDC1 ${ }^{\text {High }}$ (green) or SDC1 ${ }^{\text {Low }}$ (blue) cell populations ( $n=2$ independent experiments). gMFI values are shown. (b) (Left) A representative histogram showing the percentage of cells expressing syndecan-1 in the SDC1-KO or control cells. (Right) Binding of RBD to SDC1-KO cells normalized to control cells ( $n=2$ independent experiments). (c) Relative gene expression of PGK1 (left) and SDC1 (right) on NCl$\mathrm{H} 460$ cells cultured under normoxia or hypoxia for $24 \mathrm{~h}(n=3$, unpaired $t$ test). (d) Western blot showing the lack of HIF-1a protein in HIF1-KO NCl-H460 cells cultured under hypoxia for $24 \mathrm{~h}$. (e) Syndecan-1 expression on HIF1-KO NCl-H460 cells cultured under normoxia or hypoxia for $24 \mathrm{~h}, \mathrm{gMFI}$ values are shown. ( $\mathrm{f}$ and $\mathrm{g}$ ) Total heparan sulfate level $(f)$ and RBD binding $(g)$ on $\mathrm{HIF1-KO} \mathrm{NCI-}$ H460 cells ( $n=2$ independent experiments, unpaired t test) cultured under hypoxia for $24 \mathrm{~h}, \mathrm{gMFI}$ values are shown. Representative flow cytometry histograms including gMFI values are shown. Error bars represent SEM and asterisks represent $p$ values $\left({ }^{*} \leq .05\right.$; $\left.* *<.01 ;{ }^{* * *}<.001\right)$.

In summary, in this study we show that hypoxia decreases the binding of the spike of SARS-CoV-2 to epithelial cells by at least two different mechanisms: (1) decreasing the level of ACE2 and NRP1 expression; and (2) reducing the total amount of cellular HS (attachment factor) and syndecan-1 on the cell surface of epithelial cells.

\section{Limitations of the study}

All experiments presented here have been performed in vitro with immortalized cell lines. The significance of these findings at physiopathological oxygen levels in vivo remains unexplored. In this context, the use of humanized mouse models and real SARS-CoV-2 virus would reinforce the findings of this study. 


\section{Acknowledgements}

The plasmids for the generation of pseudotyped lentiviral particles were kindly provided by Dr Jesse D. Bloom (Fred Hutchinson Cancer Research Center) and Dr Jean-Philippe Julien (The Hospital for Sick Children). Vero E6 monkey kidney cells were kindly provided by Dr. Nicola G.A. Abrescia (CIC bioGUNE).

\section{Disclosure statement}

No potential conflict of interest was reported by the author (s).

\section{Funding}

This research was supported by the SPRI I+D COVID-19 fund (Basque Government, bG-COVID-19), the European Research Council (ERC) (grant numbers: ERC-2018-StG 804236-NEXTGEN-IO to A.P and ERC-2017-AdG 788143-RECGLYCANMR to J.J-B.), the Severo Ochoa Excellence Accreditation from MCIU (SEV-2016-0644) and the FERO Foundation. Personal fellowships: E.P. (Juan de la Cierva-Formación, FJC2018-035449-I), L.V. (Juan de la Cierva-Formación, FJCI-2017-34099), A.B. (AECC Bizkaia Scientific Foundation, PRDVZ19003BOSC), A.G. (Programa Bikaintek from the Basque Government, 48-AF-W1-2019-00012), A.A (La Caixa Inphinit, LCF/BQ/ DR20/11790022), B.J. (Basque Government, PRE_2019_1_0320), L.M. (Juan de la Cierva-Formación, FJC2019-039983-I), E.B. (MINECO, BFU2016-76872-R; Excellence Networks, SAF2017-90794-REDT) and A.P. (Ramón y Cajal, RYC2018-024183-I; Proyectos I+D+I, PID2019-107956RA-I00; and Ikerbasque Research Associate).

\section{ORCID}

Endika Prieto-Fernández (D) http://orcid.org/0000-00018378-1495

Leire Egia-Mendikute (D) http://orcid.org/0000-0002-64351219

Laura Vila-Vecilla (D) http://orcid.org/0000-0001-5573-4886 Alexandre Bosch (D) http://orcid.org/0000-0002-3022-7463 Adrián Barreira-Manrique (D) http://orcid.org/0000-00019893-6701

So Young Lee (D) http://orcid.org/0000-0003-3130-785X

Ana García-del Río (D) http://orcid.org/0000-0001-97915191

Asier Antoñana-Vildosola (D) http://orcid.org/0000-00021404-6398

Borja Jiménez-Lasheras (D) http://orcid.org/0000-0002-11817492

Leire Moreno-Cugnon (D) http://orcid.org/0000-0003-12836414

Jesús Jiménez-Barbero (D) http://orcid.org/0000-0001-54218513

Edurne Berra (D) http://orcid.org/0000-0002-3820-5744

June Ereño-Orbea (D) http://orcid.org/0000-0002-5076-2105 Asis Palazon (D) http://orcid.org/0000-0002-7172-7229

\section{References}

[1] Abdool Karim SS, de Oliveira T. New SARS-CoV-2 variants - clinical, public health, and vaccine implications. N Engl J Med. 2021 Mar 24. doi: 10.1056/NEJMc2100362. PubMed PMID: 33761203; PubMed Central PMCID: PMCPMC8008749.

[2] Wang GL, Wang ZY, Duan LJ, et al. Susceptibility of circulating SARS-CoV-2 variants to neutralization. N Engl J Med. 2021 Apr 6. doi: 10.1056/ NEJMc2103022. PubMed PMID: 33822491.

[3] Yan R, Zhang Y, Li Y, et al. Structural basis for the recognition of SARS-CoV-2 by full-length human ACE2. Science. 2020 Mar 27;367(6485):1444-1448. doi: 10.1126/science.abb2762. PubMed PMID: 32132184; PubMed Central PMCID: PMCPMC7164635.

[4] Walls AC, Park YJ, Tortorici MA, et al. Structure, function, and antigenicity of the SARS-CoV-2 spike glycoprotein. Cell. 2020;181(2):281-292.e6. doi: 10.1016/j.cell.2020.02.058. PubMed PMID: 32155444; PubMed Central PMCID: PMCPMC7102599.

[5] Clausen TM, Sandoval DR, Spliid CB, et al. SARSCoV-2 infection depends on cellular heparan sulfate and ACE2. Cell. 2020;183(4):1043-1057.e15. doi: 10.1016/j.cell.2020.09.033. PubMed PMID: 32970989; PubMed Central PMCID: PMCPMC7489987.

[6] Cantuti-Castelvetri L, Ojha R, Pedro LD, et al. Neuropilin-1 facilitates SARS-CoV-2 cell entry and infectivity. Science. 2020;370(6518):856-860. doi: 10.1126/science.abd2985. PubMed PMID: 33082293; PubMed Central PMCID: PMCPMC7857391.

[7] Daly JL, Simonetti B, Klein K, et al. Neuropilin-1 is a host factor for SARS-CoV-2 infection. Science. 2020;370(6518):861-865. doi: 10.1126/science.abd3072. PubMed PMID: 33082294.

[8] Hoffmann M, Kleine-Weber H, Schroeder S, et al. SARS-CoV-2 cell entry depends on ACE2 and TMPRSS2 and is blocked by a clinically proven protease inhibitor. Cell. 2020;181(2):271-280.e8. doi: 10.1016/j.cell.2020.02.052. PubMed PMID: 32142651; PubMed Central PMCID: PMCPMC7102627.

[9] Sarrazin S, Lamanna WC, Esko JD. Heparan sulfate proteoglycans. Cold Spring Harb Perspect Biol. 2011;3(7). doi: 10.1101/cshperspect.a004952. PubMed PMID: 21690215; PubMed Central PMCID: PMCPMC3119907.

[10] Parimon T, Yao C, Habiel DM, et al. Syndecan-1 promotes lung fibrosis by regulating epithelial reprogramming through extracellular vesicles. JCI Insight. 2019 Aug 8;5, doi: 10.1172/jci.insight.129359. PubMed PMID: 31393853; PubMed Central PMCID: PMCPMC6777916.

[11] $\mathrm{Hu}$ Y, Meng X, Zhang F, et al. Thein vitroantiviral activity of lactoferrin against common human coronaviruses and SARS-CoV-2 is mediated by targeting the heparan sulfate co-receptor. Emerg Microbes Infect. 2021;10(1):317-330. doi: 10.1080/ 22221751.2021.1888660. PubMed PMID: 33560940; PubMed Central PMCID: PMCPMC7919907.

[12] Caputo ND, Strayer RJ, Levitan R. Early self-proning in awake, Non-intubated patients in the emergency department: A single ED's experience during the COVID-19 pandemic. Acad Emerg Med. 2020;27(5):375-378. doi: 10.1111/acem.13994. PubMed PMID: 32320506; PubMed Central PMCID: PMCPMC7264594.

[13] Berenguer J, Ryan P, Rodriguez-Bano J, et al. Characteristics and predictors of death among 4035 consecutively hospitalized patients with COVID-19 in Spain. Clin Microbiol Infect. 2020;26(11):15251536. doi: $10.1016 /$ j.cmi.2020.07.024. PubMed PMID: 32758659; PubMed Central PMCID: PMCPMC7399713. 
[14] Petrilli CM, Jones SA, Yang J, et al. Factors associated with hospital admission and critical illness among 5279 people with coronavirus disease 2019 in New York city: prospective cohort study. Br Med J. 2020;369:m1966. doi: 10.1136/bmj.m1966. PubMed PMID: 32444366; PubMed Central PMCID: PMCPMC7243801.

[15] Yadaw AS, Li YC, Bose S, et al. Clinical features of COVID-19 mortality: development and validation of a clinical prediction model. Lancet Digit Health. 2020;2(10):e516-e525. doi: 10.1016/S2589-7500 (20)30217-X. PubMed PMID: 32984797; PubMed Central PMCID: PMCPMC7508513.

[16] Egia-Mendikute L, Bosch A, Prieto-Fernández E, et al. Sensitive detection of SARS-CoV-2 seroconversion by flow cytometry reveals the presence of nucleoproteinreactive antibodies in unexposed individuals. Commun Biol. 2021;4(1):486), doi: 10.1038/s42003021-02011-6. PubMed PMID: 33879833.

[17] Berlin DA, Gulick RM, Martinez FJ. Severe covid-19. N Engl J Med. 2020;383(25):2451-2460. doi: 10.1056/NEJMcp2009575. PubMed PMID: 32412710.

[18] Afsar B, Kanbay M, Afsar RE. Hypoxia inducible factor-1 protects against COVID-19: a hypothesis. Med Hypoin Vitros. 2020 Oct;143(109857). doi: 10.1016/ j.mehy.2020.109857. PubMed PMID: 32464493; PubMed Central PMCID: PMCPMC7238987.

[19] Couzin-Frankel J. The mystery of the pandemic's 'happy hypoxia'. Science. 2020;368(6490):455-456. doi: 10.1126/science.368.6490.455. PubMed PMID: 32355007.

[20] Arias-Reyes C, Zubieta-DeUrioste N, Poma-Machicao $\mathrm{L}$, et al. Does the pathogenesis of SARS-CoV-2 virus decrease at high-altitude? Respir Physiol Neurobiol. 2020;277:103443. doi: 10.1016/j.resp.2020.103443. PubMed PMID: 32333993; PubMed Central PMCID: PMCPMC7175867.

[21] Paizis G, Tikellis C, Cooper ME, et al. Chronic liver injury in rats and humans upregulates the novel enzyme angiotensin converting enzyme 2. Gut. 2005;54(12):1790-1796. doi: 10.1136/ gut.2004.062398. PubMed PMID: 16166274; PubMed Central PMCID: PMCPMC1774784.

[22] Zhang R, Wu Y, Zhao M, et al. Role of HIF-1 $\alpha$ in the regulation $\mathrm{ACE}$ and $\mathrm{ACE} 2$ expression in hypoxic human pulmonary artery smooth muscle cells. Am J Physiol Lung Cell Mol Physiol. 2009;297(4):L631L640. doi: 10.1152/ajplung.90415.2008. PubMed PMID: 19592460.

[23] Zhang R, Su H, Ma X, et al. MiRNA let-7b promotes the development of hypoxic pulmonary hypertension by targeting ACE2. Am J Physiol Lung Cell Mol Physiol. 2019;316(3):L547-L557. doi: 10.1152/ ajplung.00387.2018. PubMed PMID: 30628484.

[24] Joshi S, Wollenzien H, Leclerc E, et al. Hypoxic regulation of angiotensin-converting enzyme 2 and Mas receptor in human CD34+cells. J Cell Physiol. 2019;234(11):20420-20431. doi: 10.1002/jcp.28643. PubMed PMID: 30989646; PubMed Central PMCID: PMCPMC6660366.

[25] Clarke NE, Belyaev ND, Lambert DW, et al. Epigenetic regulation of angiotensin-converting enzyme 2 (ACE2) by SIRT1 under conditions of cell energy stress. Clin Sci (Lond). 2014;126(7):507-516. doi: 10.1042/CS20130291. PubMed PMID: 24147777.

[26] Asplund A, Ostergren-Lunden G, Camejo G, et al. Hypoxia increases macrophage motility, possibly by decreasing the heparan sulfate proteoglycan biosynthesis. J Leukoc Biol. 2009;86(2):381-388. doi: 10.1189/jlb.0908536. PubMed PMID: 19401393.

[27] Wu F, Wang JY, Chao W, et al. miR-19b targets pulmonary endothelial syndecan-1 following hemorrhagic shock. Sci Rep. 2020;10(1):15811), doi: 10.1038/ s41598-020-73021-3. PubMed PMID: 32978505; PubMed Central PMCID: PMCPMC7519668.

[28] Taniguchi-Ponciano K, Vadillo E, Mayani H, et al. Increased expression of hypoxia-induced factor $1 a$ mRNA and its related genes in myeloid blood cells from critically ill COVID-19 patients. Ann Med. 2021;53(1):197-207. doi: 10.1080/ 07853890.2020.1858234. PubMed PMID: 33345622; PubMed Central PMCID: PMCPMC7784832.

[29] Crawford KHD, Eguia R, Dingens AS, et al. Protocol and reagents for pseudotyping lentiviral particles with SARS-CoV-2 spike protein for neutralization assays. Viruses. 2020 May 6;12(5). doi: 10.3390/ v12050513. PubMed PMID: 32384820; PubMed Central PMCID: PMCPMC7291041.

[30] Ma D, Chen CB, Jhanji V, et al. Expression of SARSCoV-2 receptor ACE2 and TMPRSS2 in human primary conjunctival and pterygium cell lines and in mouse cornea. Eye (Lond). 2020;34(7):1212-1219. doi: 10.1038/s41433-020-0939-4. PubMed PMID: 32382146; PubMed Central PMCID: PMCPMC7205026.

[31] Reynolds MR, Singh I, Azad TD, et al. Heparan sulfate proteoglycans mediate $A \beta$-induced oxidative stress and hypercontractility in cultured vascular smooth muscle cells. Mol Neurodegener. 2016;11:9), doi: 10.1186/s13024-016-0073-8. PubMed PMID: 26801396; PubMed Central PMCID: PMCPMC4722750.

[32] Casazza A, Laoui D, Wenes M, et al. Impeding macrophage entry into hypoxic tumor areas by Sema3A/ Nrp1 signaling blockade inhibits angiogenesis and restores antitumor immunity. Cancer Cell. 2013;24 (6):695-709. doi: 10.1016/j.ccr.2013.11.007. PubMed PMID: 24332039.

[33] Lang J, Yang N, Deng J, et al. Inhibition of SARS pseudovirus cell entry by lactoferrin binding to heparan sulfate proteoglycans. PLoS One. 2011;6(8):e23710. doi: 10.1371/journal.pone.0023710. PubMed PMID: 21887302; PubMed Central PMCID: PMCPMC3161750.

[34] Appelberg S, Gupta S, Svensson Akusjarvi S, et al. Dysregulation in Akt/mTOR/HIF-1 signaling identified by proteo-transcriptomics of SARS-CoV-2 infected cells. Emerg Microbes Infect. 2020;9 (1):1748-1760. doi: 10.1080/22221751.2020.1799723. PubMed PMID: 32691695; PubMed Central PMCID: PMCPMC7473213.

[35] Gan ES, Ooi EE. Oxygen: viral friend or foe? Virol J. 2020;17(1):115. doi: 10.1186/s12985-020-01374-2. PubMed PMID: 32718318; PubMed Central PMCID: PMCPMC7385969.

[36] Palazon A, Goldrath AW, Nizet V, et al. HIF transcription factors, inflammation, and immunity. Immunity. 2014;41(4):518-528. doi: 10.1016/ j.immuni.2014.09.008. PubMed PMID: 25367569; PubMed Central PMCID: PMCPMC4346319.

[37] Zhang Q, Chen CZ, Swaroop M, et al. Heparan sulfate assists SARS-CoV-2 in cell entry and can be targeted by approved drugs in vitro. Cell Discov. 2020;6 (1):80. doi: 10.1038/s41421-020-00222-5. PubMed 
PMID: 33298900; PubMed Central PMCID: PMCPMC7610239.

[38] Wing PAC, Keeley TP, Zhuang X, et al. Hypoxic and pharmacological activation of HIF inhibits SARSCoV-2 infection of lung epithelial cells. Cell Rep. 2021 Apr 5;109020, doi: 10.1016/j.celrep.2021.109020. PubMed PMID: 33852916.

[39] Poloznikov AA, Nersisyan SA, Hushpulian DM, et al. HIF prolyl hydroxylase inhibitors for COVID-19 treatment: pros and cons. Front Pharmacol. 2020;11 (621054). doi: 10.3389/fphar.2020.621054. PubMed PMID: 33584306; PubMed Central PMCID: PMCPMC7878396.

[40] Taylor CT, Colgan SP. Regulation of immunity and inflammation by hypoxia in immunological niches. Nat Rev Immunol. 2017;17(12):774-785. doi: 10.1038/nri.2017.103. PubMed PMID: 28972206; PubMed Central PMCID: PMCPMC5799081.

[41] Rius J, Guma M, Schachtrup C, et al. NF- $\kappa B$ links innate immunity to the hypoxic response through transcriptional regulation of HIF-1a. Nature.
2008;453(7196):807-811. doi: 10.1038/nature06905. PubMed PMID: 18432192; PubMed Central PMCID: PMCPMC2669289.

[42] Merad M, Martin JC. Pathological inflammation in patients with COVID-19: a key role for monocytes and macrophages. Nat Rev Immunol. 2020;20 (6):355-362. doi: 10.1038/s41577-020-0331-4. PubMed PMID: 32376901; PubMed Central PMCID: PMCPMC7201395.

[43] Zhu B, Wu Y, Huang S, et al. Uncoupling of macrophage inflammation from self-renewal modulates host recovery from respiratory viral infection. Immunity. 2021 Apr 28. doi: 10.1016/ j.immuni.2021.04.001. PubMed PMID: 33951416.

[44] Codo AC, Davanzo GG, Monteiro LB, et al. Elevated glucose levels favor SARS-CoV-2 infection and monocyte response through a HIF-1 $\alpha /$ glycolysis-dependent axis. Cell Metab. 2020;32(3):437-446.e5. e5. doi: 10.1016/j.cmet.2020.07.007. PubMed PMID: 32697943; PubMed Central PMCID: PMCPMC7367032. 